\title{
On Exemplifying Markers in Present-day BRITISH AND AMERICAN ENGLISH: FORMAL AND FUNCTIONAL IMPLICATIONS
}

\begin{abstract}
The aim of this paper is to provide a formal and functional analysis of a selection of four English exemplifying markers, namely including, included, for example and for instance. The analysis unveils some recent ongoing changes which point at the broadening of the structural scope of including (which used to link exclusively non phrases in the past but can now be used with a wider variety of syntactic forms) and an increasing discursive use of for example and for instance (both tend to connect whole chunks of discourse and seem to be developing pragmatic meanings, especially - but not exclusively - as mitigators). The corpus-driven study is based on the texts of the Brown family of corpora, which allows the identification of any potential diachronic variation observed at three points in present-day English (namely, the 1960s, the 1990s and the 2000s) in both British and American English.
\end{abstract}

Keywords

Exemplification; exemplifying marker; grammaticalization; syntagmatic variability; structural scope

\section{Introduction}

Examples are discursive instruments which make previous, more general statements easier to follow. Being episodic and concrete, examples are considered an essential part of higher forms of thought. They have a deeper impact on the interlocutor than the general assertions they accompany given their strong persuasive power (see Brosius and Bathelt 1994: 48-50, Gibson and Zillmann 
1994: 605, Perry and Gonzenbach 1997: 230-232 and Lischinsky 2008: 244, 247 , among others). Besides being a good tool for persuasion and making a text more graspable and easier to understand, examples are also ornamental elements which enrich the text (Lyons 1989: 17). Moreover, they also constitute a relief in the writer's abstract discourse and make the text more accessible for the reader (Hyland 2007: 282). The present paper approaches this discursive strategy from a syntactic perspective and describes exemplifying constructions in present-day English. Prototypical exemplification (as in (1)) entails a relation of partial coreferentiality between two units: the first unit (a few countries in (1), which I will call general element or GE), has a wider referent, whereas the second unit (Chile, Ghana, and Indonesia, the exemplifying element or EE), refers anaphorically to one or several members included in the GE, but it never provides the whole list of items which comprise the GE; in other words, the EE is an example of the GE (cf. Hyland 2007: 270).

(1) A few countries (for example, Chile, Ghana, and Indonesia) have increased the relative share of aggregate social sector expenditures as well as expenditures on basic social services. (FROWN, H11 188) ${ }^{1}$

The example provided is chosen from a set of other potential representatives, all of them sharing the essential features of the GE. Therefore, all the members included in that GE can indeed represent or exemplify the group attributes, although bringing different individual characteristics into focus (Zillmann and Brosius 2000: 3). Given that exemplification entails a relation between two units, it has traditionally been classified as a type of apposition, although a non-prototypical one since a relation of partial co-referentiality (rather than full co-referentiality) exists between the two units (see Quirk et al. 1985: 1315 or Meyer 1992: 77). An explicit link between the GE and the EE is compulsory in order to make clear the semantic relation of inclusion existing between the GE and the EE (although on occasion they can be used implicitly by means of a pause in the oral domain or by different punctuation marks in written texts; cf. Lyons 1989: 26 or Fernández-Bernárdez 1994-5: 106, among others). This link is the exemplifying marker (EM). Thus, if we omit the EM for example in (1) above, the EE (i.e. Chile, Ghana, and Indonesia) would in fact represent the whole list of countries referred to in the GE. As a consequence, this would be a case of reformulation rather than one of exemplification. In present-day English (PDE), the list of forms that may function as EMs is the following: including, included, for example, for instance, e.g., like, such as, as and say (Quirk et al. 1985: 1315-1316). ${ }^{2}$ The present paper provides a formal and functional analysis of four of these EMs in present-day British English (henceforth BrE) and American English (AmE), namely including, included, for example and for instance. These four forms have been selected because they can be easily grouped into two different sets of EMs (that is, for example and for instance, on the one hand, and including and included, on the other) due to their enormous formal similarities. 
The aim of this paper is to investigate the behavior of the two sets of EMs selected in order to find out whether further differences between the two sets of EMs can be identified beyond their form. Along similar lines, intraset differences will also be explored. The analysis will be addressed from the perspective of grammaticalization, which is "the change whereby lexical items and constructions come in certain linguistic contexts to serve grammatical functions and, once grammaticalized, continue to develop new grammatical functions" (Hopper and Traugott 2003: 18; see also Kuryłowicz 1975, Langacker 1977, Brinton and Traugott 2005 or Lightfoot 2011, among many others). More specifically, the paper focuses on two of Lehmann's (2002) parameters of grammaticalization, namely the reduction of structural scope of the grammaticalized items and the loss of their syntagmatic variability. The research questions addressed here are the following:

RQ1: Which sentential slots do the EMs under analysis occupy in the exemplifying sequence? Which pragmatic implications are derived from those different positions?

RQ2: How has the process of grammaticalization undergone by these four items in order to become EMs affected their structural scope?

RQ1 is rather transparent: it deals with the different positions which the four selected forms may occupy in relation to the EE and the potential pragmatic meanings derived from those positions. The question becomes especially pertinent in the case of for example and for instance, as they have considerable syntagmatic freedom within the exemplifying sequence. Therefore, different pragmatic meanings are expected to derive from the position which they occupy in relation to the example that they introduce. In turn, RQ2 may need further elaboration. Thus, taking into account the prepositional status of including and included, ${ }^{3}$ we expect to find exclusively nominal units in exemplification with these two forms, as in (2) and (3) below, where the GEs are the ten largest cities and most states, respectively, whereas the EEs are New York and Arkansas and Louisiana. In turn, for example and for instance seem to be able to link a wider variety of syntactic forms, not only NPs as in (1) above (where GE is a few countries and the EE Chile, Ghana, and Indonesia), but also whole sentences, as in (4) and (5). In these two examples, the anaphoric connection holds between whole sentences rather than phrases.

(2) Now, a close look at the schools in and around the ten largest cities, including New York, has shattered this optimism. (BROWN, B07 1390)

(3) Most states, Arkansas and Louisiana included, spend less than the minimum recommended by the federal government on anti-smoking programs. (AE06, B) 
(4) In the adult world, there are a number of rather general and diffuse sources of ideological diffusion that further compound the adolescent's search for meaning during this particular identity crisis. For example, some contemporary writing tends to fuse the "good guys" and the "bad guys", to portray the weak people as heroes and weakness as a virtue, and to explain (or even justify) asocial behavior by attributing it to deterministic psychological, familial, and social experiences.

(BROWN, F39 2020)

(5) All the murders were well documented and had the air of being written by an ingenious, but mad film director of the Thirties. They mostly occurred in lonely farm-houses. Monsieur H, for instance, had been clubbed and throttled to death by his wife, children and father-in-law, after muddling up some sheep while the worse for drink. (LOB, R06 57)

For our purposes, the Brown family of corpora is used as the main source of information as they allow the analysis of these four forms at three different points in time in PDE: the 1960s, the 1990s and the 2000s. For the British variety, the data come from the Lancaster-Oslo-Bergen Corpus of British English (LOB; compilation date: 1961), the Freiburg-Lancaster-Oslo-Bergen Corpus of British English (FLOB; compilation date: 1991) and the British English 2006 (BE06; compilation date: 2006). As for the American variety, the corpora consulted are the Brown Corpus of American English (BROWN; compilation date: 1961), the Freiburg-Brown Corpus of American English (FROWN; compilation date: 1992) and the American English 2006 (AE06; compilation date: 2006). These are multi-genre parallel (and thus comparable) corpora consisting of over 1 million words each. These corpora were selected in order to examine whether there is any dialectal (British vs. American English) or diachronic (1960s vs. 1990s vs. 2000 s) variation in the use of the four selected markers. The six corpora provide a total of 2984 instances of including, included, for example and for instance as EMs.

The paper is organized as follows. Section 2 provides the analysis of the corpus data. It opens with a general overview of the use of the four selected forms taking the decade and the variety into consideration. Then, the analysis focuses on each set of markers, namely including and included in Section 2.1, and for example and for instance in Section 2.2. Section 3 closes the paper and draws the main conclusions from the corpus-based contrastive analysis.

\section{Including, included, for example and for instance in present-day British and American English}

Before the detailed analysis of each set of EMs, an overview of the data analyzed per period and variety is in order. This is given in Table 1 below. 
Table 1. Distribution of including, included, for example and for instance according to subperiod and variety of English

\begin{tabular}{|r|c|c|c|c|c|c|c|c|}
\hline & \multicolumn{4}{|c|}{ British English } & \multicolumn{4}{c|}{ American English } \\
\cline { 2 - 10 } & $\begin{array}{c}\text { LOB } \\
{[\mathbf{1 9 6 0 s}]}\end{array}$ & $\begin{array}{c}\text { FLOB } \\
{[\mathbf{1 9 9 0 s}]}\end{array}$ & $\begin{array}{c}\text { BE06 } \\
{[\mathbf{2 0 0 0 s}]}\end{array}$ & Total & $\begin{array}{c}\text { BROWN } \\
{[\mathbf{1 9 6 0 s}]}\end{array}$ & $\begin{array}{c}\text { FROWN } \\
{[\mathbf{1 9 9 0 s}]}\end{array}$ & $\begin{array}{c}\text { AE06 } \\
{[\mathbf{2 0 0 0 s}]}\end{array}$ & Total \\
\hline Including & 130 & 224 & 274 & 628 & 135 & 218 & 322 & 675 \\
\hline Included & 1 & 3 & 3 & 7 & - & - & 3 & 3 \\
\hline For example & 141 & 270 & 242 & 653 & 173 & 243 & 233 & 649 \\
\hline For instance & 92 & 83 & 40 & 215 & 52 & 46 & 56 & 154 \\
\hline Total & 364 & 580 & 559 & 1,503 & 360 & 507 & 614 & 1,481 \\
\hline
\end{tabular}

By and large, including (1,303 examples, $43.7 \%$ of the total number of EMs in the material analyzed) and for example (1,302 examples, $43.6 \%$ of the total) are clearly the preferred options in the corpora, while the use of included is very sporadic (only ten occurrences of this marker, $0.3 \%$ of the total). As for for instance, the frequency for this marker is comparatively lower as well (369 examples, $12.4 \%$ of the total). The raw figures for the two varieties of English under analysis here suggest a similar use of exemplifying constructions with the four EMs: 1,503 exemplifying constructions in the BrE corpora and 1,481 in the AmE material. If we compare the use of exemplifying constructions regardless of the EM and variety of English in the three subperiods analyzed, we can conclude that such constructions become more frequent across time. Thus, 724 cases are attested in the data from the 1960s, and the number rises in the two subsequent subperiods: 1,087 cases in the 1990s and 1,173 in the 2000s. This upwards tendency suggests that exemplification is becoming increasingly more common as a discourse strategy, hence the need of further research on the topic.

\section{Including and included in British and American English}

According to the corpora consulted, the etymologically related EMs including and included (they both derive from the verb to include; OED s.v. include v.6) occupy a fixed position in relation to the EE, thus showing division of labor: in all the corpus examples, including invariably precedes the EE (cf. (2) above: including New York), whereas included follows it (cf. (3): Arkansas and Louisiana included). This clear pattern of distribution is the result of a process of fixation (cf. Lehmann 2002: 146), and one of the outcomes of the process of grammaticalization that these forms have undergone in order to become markers of exemplification. In close connection with this, König and Kortmann (1991: 114) claim that most de-verbal prepositions (i.e. prepositions deriving from verbs) precede their complement, just like including. Curiously enough, they illustrate this by listing mostly -ing forms (during, pending, failing). However, they make clear that certain forms have fossilized in post-nominal position; such is the case of ago (a phonologically reduced form of agone; see König and Kortmann 1991: 117) and excepted, both past participle forms (like included). Therefore, there seems to 
be a tendency for prepositions deriving from present participles to precede their complements, whereas those stemming from past participles very often (though not exclusively) follow them.

As regards the syntactic forms of the units which appear in exemplification with these two markers, included exclusively links nominal units (as in (3) above). On its part, including also shows a clear preference for a nominal environment: it takes nominal GEs in at least $98 \%$ of its corpus occurrences in both varieties, a percentage which is slightly lower in the case of the EE $(96 \%$ of its corpus occurrences). In this regard, Pullum and Huddleston (2002: 611) ${ }^{4}$ claim that including is a preposition and, just like other prepositions which are homonymous with either the present or past participles of verbs (such as concerning or given), it takes NPs as its complement. Moreover, and given that NP is the most common type of syntactic form with this marker as both GE and EE, these sequences are semantically and syntactically similar to sentences where the verb to include takes a direct object. In this regard, König and Kortmann (1991: 113) notice the analogous relationship between non-finite verbal forms and their complements, on the one hand, and adpositional (both pre- and postpositinal) phrases. In fact, exemplification with including and included could be replaced by a relative clause with the verb to include. Let us take example (2) above as a case in point: here, the exemplifying sequence can be rephrased as "the ten largest cities, which include New York". Notice that this rephrasing is possible because the verb to include, the source form of these EMs, has not disappeared after the grammaticalization of this marker. In fact, both forms survive up to the present-day showing divergence (see Hopper 1991: 24 and Hopper and Traugott 2003: 118) of functions, though traces of the source meaning still remain in the EM (this is known as persistence; see Hopper 1991: 22). However, in other cases the source form dies out from the language and only the new, grammaticalized item survives (cf. Bybee 2003: 161). The preposition during, whose origin is to be found in the obsolete verb *dure (cf. French durer 'to last), is one of such instances:

The prepositional status of during is the result of a reanalysis of the phrase type during NP in sentences such as During the storm, we remained inside: originally, during NP (also NP during) was a nominative absolute construction having NP as its subject (e.g. '(with) the storm lasting'), but its gradual disassociation from the obsolescent verb *dure led to its reinterpretation as a prepositional phrase. Thus, although the function word during derives from a verb, it does so through a historical process of grammaticalization.

(Stump 2009: 319)

However, the analysis of more recent data shows that, even though statistically insignificant, syntactic forms other than NPs are now possible in exemplifying constructions with this marker, especially in the EE. Let us consider some of these instances. On the one hand, including may link clauses, both -ing clauses and nominal relative clauses (i.e. those where the $w h$-relativizer is merged with 
its antecedent; Quirk et al. 1985: 1056). For example, in (6) below the GE is an -ing clause and the EE a nominal relative clause. Interestingly, these two types of clauses are very close to NPs in their behavior, thus reinforcing the tendency identified for including to link nominal (or nominal-like) units. I have also identified three adjective phrases, as exemplified in (7) below. In these cases, the construction seems to involve some kind of ellipsis: in (7), the sequence special (including vocational) is an elliptical form of special interest, including vocational interest, which would be a prototypical case of nominal exemplification, though too repetitive to sound natural.

(6) She stayed for just a year, but gained an insight into what was required, including recording techniques. (FLOB, E11 192)

(7) They also run short courses for special (including vocational) interest. (FLOB, H21 163)

So far, the use of non-nominal units with including is not hard to explain as, upon closer inspection, such units do not significantly differ from NPs. However, the justification of other types of syntactic forms in exemplification with including, such as adverb phrases, prepositional phrases (cf. (8) and (9)) or sentences (cf. (10)), may be more challenging. Let us consider some illustrative examples.

(8) The segment was aired nation-wide, including on the West Coast, where the show is tape delayed. (FROWN, A22 38)

(9) They are patriots who, once committed, commit on all levels, including emotionally. (AE06, A)

(10) Tightening supply and demand, and regulatory changes are producing significant effects, according to the study, including:

- Gas price will be more volatile and less predictable on seasonal patterns

- Competitive restructuring and realignment among producers, pipelines, marketers and distribution companies driven by FERC Order 636 and a tightening market will benefit merchants who can provide flexible, reliable supply. (FROWN, E33 23)

Examples (8) and (9) display the same types of units in exemplification but in different arrangements: in (8), the GE is an adverbial phrase and the EE a prepositional phrase, whereas in (9) it is exactly the other way around. These two instances represent weak exemplification as different types of units appear in the GE and the EE. ${ }^{5}(10)$, in turn, is even more complex as the EE consists of two sentences listed in bullet points. In these instances, including seems to be broadening its structural scope (cf. Lehmann 2002) beyond its original domain as it 
takes units which challenge its status as a preposition. In close connection with this, in his work on the grammaticalization of complex prepositions in English, Hoffmann (2005: 129) categorically denies the prepositional status of in terms of in example (11) below due to the type of unit which follows it, namely an adverb phrase (money-wise). In like manner, (12) cannot illustrate a prepositional use of the phrase since it takes an adverbial clause (when you are taking so much into consideration).

(11) What I will do is emphasize what we you know where you can go in terms of money-wise. (Hoffmann 2005: 129; BNC: JA4: 167)

(12) Sue: I think the management thing can be addressed in a different way $<$ cough $>$ erm excuse me erm, oh I've lost my thread now but, oh yeah that's [right]

Keith: [Yeah.]

Sue: in terms of when you're taking so much into consideration, the actual lo- loading or weighting of that factor would actually s- turn into $\mathrm{dr}-$ into something very insignificant in terms of weighting I think.

(Hoffmann 2005: 126-127; BNC: H5D: 1088-1098)

These and other examples are adduced by the author in order to point at the use of in terms of as a discourse marker rather than as a complex preposition in presentday English. Examples (11)-(12) with in terms of bear a resemblance to (8)-(10) above with including in that they link similar types of units. In light of these examples, we might be witnessing a further step in the process of grammaticalization of including, which might bring this form closer to the category of discourse markers.

As expected from the overwhelming prevalence of NPs in exemplification with these two markers, the great majority of the functions carried out by exemplifying constructions with including and included are those typically associated with NPs, such as complement of a preposition (cf. (2) above: around the ten largest cities, including New York; (6): into what was required, including recording techniques; and (7): for special (including vocational)), direct object (cf. (13) below), subject (cf. (14)) or subjective predicative complement (cf. (15)).

(13) Then tell him your non-negotiables, including respect (no name calling when they argue) and maintaining relationships with his other friends and his family. $(\mathrm{AE} 06, \mathrm{~F})^{6}$

(14) In the middle of the 19th century, western and northern Europeans, including more than 5 million Irish and Germans, dominated the influx to the United States. (AE06, J) 
(15) This opened the way for the development to begin but, as will be seen later, there were still several difficulties to be overcome including worries abut $<$ sic $>$ the legality of the action being taken. (FLOB, G51 147)

Nevertheless, examples (8) and (9) discussed above are highly interesting as they show the use of exemplifying sequences with including in a clausal slot which is not typically occupied by NPs: they are place adjuncts ((8): was aired nationwide, including on the West Coast; (9): committed on all levels, including emotionally), which again point at the broader structural scope of including in some recent examples.

\section{For example and for instance in British and American English}

When it comes to the position that for example and for instance may occupy in the exemplifying sequence, the markers show syntagmatic variability (Lehmann 2002: 146) as they may either precede, follow or intervene in the middle of the EE. I will refer to initial, final and middle positions as P1 (see (4) above, repeated below as (16) for ease of reference), P2 (see (5) above, given below as (17)) and P3 (cf. (18) below), respectively. ${ }^{7}$

(16) In the adult world, there are a number of rather general and diffuse sources of ideological diffusion that further compound the adolescent's search for meaning during this particular identity crisis. For example, some contemporary writing tends to fuse the "good guys" and the "bad guys", to portray the weak people as heroes and weakness as a virtue, and to explain (or even justify) asocial behavior by attributing it to deterministic psychological, familial, and social experiences.

(BROWN, F39 2020)

(17) All the murders were well documented and had the air of being written by an ingenious, but mad film director of the Thirties. They mostly occurred in lonely farm-houses. Monsieur H, for instance, had been clubbed and throttled to death by his wife, children and father-in-law, after muddling up some sheep while the worse for drink. (LOB, R06 57)

(18) "I speak French as well as Italian and German, and can converse on a variety of subjects secular or religious. I've helped tutor young men in Latin, and I've had sufficient training in mathematics, geography, and economics." "It seems you're talented in a variety of tasks, Miss Sinclair. However, you need not narrow your employment to that of a governess. You could be suitable for a diversity of employment, such as a milliner's assistant or a barmaid, for example." "I've no interest in hats, and while I don't object to spirits because of any moral stance, I simply can not abide the smell of ale." (AE06, P07) 
As shown in Table 2 below, $\mathrm{P} 1$ is always the preferred position with both for example and for instance, especially in $\mathrm{BrE}$, followed by $\mathrm{P} 2$, which is in turn more common in the American variety. P3 is rather marginal with the two EMs under analysis.

Table 2. Position of for example and for instance in the exemplifying sequence in $\mathrm{BrE}$ and $\mathrm{AmE}$

\begin{tabular}{|l|l|c|c|c|c|c|c|}
\hline \multicolumn{2}{|c|}{} & \multicolumn{2}{c|}{ P1 } & \multicolumn{2}{c|}{ P2 } & \multicolumn{2}{c|}{ P3 } \\
\cline { 3 - 8 } \multicolumn{2}{|c|}{ For example } & BrE & AmE & BrE & AmE & BrE & AmE \\
\cline { 2 - 8 } & $\%$ & 345 & 408 & 146 & 190 & 51 & 51 \\
\hline \multirow{3}{*}{ For instance } & Tokens & 70 & 62 & 22 & 30 & 8 & 8 \\
\cline { 2 - 8 } & $\%$ & 59 & 46 & 32 & 42 & 10 & 12 \\
\hline
\end{tabular}

Even though a breakdown of the data per period is not provided because no definite trend has been identified for most positions/decade (the position of the markers fluctuates from one decade to the next without showing any clear upwards/ downwards tendency), the use of for instance in P3 deserves closer attention. In both varieties, final position becomes gradually more common from the 1960s ( $7 \%$ of the corpus instances in $\mathrm{BrE}$ and $10 \%$ in $\mathrm{AmE}$ ) to the $2000 \mathrm{~s}$ (18\% in $\mathrm{BrE}$ and $16 \%$ in $\mathrm{AmE}$ ). We will now consider the pragmatic implications which the different positions occupied by our EMs may have and will then return to the discussion of the increasing tendency of for instance to appear in P3.

The placement of these markers in different clausal slots may bring about various pragmatic inferences. ${ }^{8}$ Thus, left periphery (P1) is typically associated with text organization. As a matter of fact, this is the most neutral (i.e. less marked) position for a marker of any kind as it clearly delimits the beginning of the element that it introduces, in this case the EE (see (16) above, where for example neatly separates the GE from the EE). In turn, the placement of an EM in P2 typically responds to pragmatic reasons: it isolates a part of the $\mathrm{EE}$ and emphasizes it. In (17), the EM isolates Monsieur H, which is the subject of the sentence, thus making it more prominent. Following Wichmann, Simon-Vandenbergen and Aijmer (2010: 121), we consider that medial position applies to those cases in which the EM is post-thematic. In such cases, the EM are typically preceded by the subject or a sentence adverbial.

Finally, right periphery (P3) is usually associated with interpersonal uses: the addition of an element at the end of an utterance very often seeks the modification of the illocutionary force of the preceding statement. For example, in (18) above (a diversity of employment, such as a milliner's assistant or a barmaid, for example) the speaker is trying to convince his interlocutor that she should apply for a wider variety of jobs rather than just restricting herself to becoming a governess. However, he does not want to offend her in case she does not like his suggestions (i.e. a milliner's assistant or a barmaid), which is why he adds for example at the end in an attempt to make his words less assertive and direct. By her 
reaction (she objected to his recommendations) we can see that such a mitigating strategy was necessary. ${ }^{9}$ Let us consider one further example:

(19) Lucy wasn't used to not liking people but from the moment Guy had strolled into the kitchen a few days ago and introduced himself with that smile - the one that seemed to assume that any woman on the receiving end would instantly swoon at his feet - her normally sunny nature had deserted her. There was just something about him that rubbed her up the wrong way, leaving her irritated and edgy. [...]

"I'm surprised you're not having a go today if you were that keen [on rodeos]." she said.

"I know better now," said Guy. "I leave the hard stuff to the experts like Prince Charming over there."

He nodded across the ring to where Kevin was sitting on the rails, looking quietly confident as another wild horse pawed the ground in the chute, impatient for release into ring. "You need to be tough to take on bareback bronc riding."

"I know," said Lucy, deciding to ignore the Prince Charming jibe. "Kevin says it's the supreme rodeo challenge," she was unable to resist adding. She was at that stage of infatuation when just saying Kevin's name was a thrill.

"Kevin said something?" Guy straightened from the rail in mock astonishment. "When? I didn't know he could talk!"

"Very funny," said Lucy coldly.

"You've got to admit that he's not exactly chatty," he said. "I've hardly heard him say a word at meals since I arrived. I mean, we all know about strong silent types, but that's ridiculous!"

"There's nothing ridiculous about Kevin," Lucy flared up. "He just doesn't say anything unless it's worth saying. It's one of the things that makes him a real man - unlike some," she added pointedly.

Guy leant back against the fence and folded his arms, but Lucy was sure that behind those stupid sunglasses, his eyes were dancing.

"So you think a real man incapable of making conversation?"

"No, he just doesn't waste his time spouting stupid rubbish - like giving people silly nicknames, for instance!"

"Cinders, are you by any chance implying that you don't think I am real man?" Guy tsk-tsked. (sic) "I'm hurt!"

If Lucy had believed for a moment that he had been really offended, she would have been embarrassed, but as it was, she just lifted her chin at him.

"You're not like Kevin," she said.

"Apart from the fact that I can string more than three words together at a time, what's the real difference between us?"

"Kevin's tough," said Lucy. "He's steady, he's sensible and he works 
hard." Belatedly, she realised that she hadn't made him sound much fun, and she waited for Guy to point it out, but he only grinned. (BE06, P19)

In this long extract, we can see how Guy is trying to flirt with Cinders, and even though she pretends to dislike him, she is in fact attracted to him. In their conversation, Guy refers to another character, Kevin, with a nickname, namely Prince Charming. When later on in the conversation Cinder implicitly compares Kevin to Guy by saying that Kevin "doesn't waste his time spouting stupid rubbish - like giving people silly nicknames, for instance", she is not giving a random example. As a matter of fact, she has chosen that very example to make it clear that she does not consider the Prince Charming jibe appropriate. In this case, for instance does not act as a mitigator: the addition of the marker in final position somehow emphasizes the example selected, thus making it clear that such an instance has been chosen on purpose. As stated earlier in this section, for instance is increasingly used in $\mathrm{P} 3$, and given the pragmatic implications that this position may have, we might be witnessing a change towards greater (inter)subjectivity with this marker. To put it differently, for instance seems to be developing a stronger pragmatic function as it is increasingly used in the right periphery. For its part, for example is also possible in $\mathrm{P} 3$ (as shown in Table 2 above), but its use in this position remains stable over time.

Along with the different degree of syntagmatic variability of the two sets of EMs, a second important difference between the two sets of EMs is the type of units which they take. Sentences are the most common units in both the GE and the EE with the two periphrastic markers regardless of period or variety, although overall they are far more common in AmE than in BrE (in BrE, sentences occur in the GE in $53-58 \%$ of the total number of the corpus occurrences regardless of the EM vs. $63-67 \%$ in the EE; in AmE, sentential GEs rise up to $72-75 \%$ of the cases, and sentential EEs to 75-77\%). An example of a sentential GE is given in (4) above. A look at the origin of for example and for instance may explain why they take complex units (i.e. sentences) as both GE and EE so frequently. The two phrasal EMs consist of the preposition for followed by the nouns example/ instance, which are close synonyms..$^{10}$ As a matter of fact, in most dictionaries example is defined as 'instance' and instance as 'example'. Hence the use of these two markers in similar contexts. A close look at the OED entry for example already gives us a hint of the type of unit which may follow for example: s.v. example n., 1.d: "an illustrative or instructive narrative" (emphasis added). Therefore, the semantics of the noun example (and - though not explicitly stated in the OED - instance too) points at the long, narrative-like character of the EE introduced by these markers.

After sentences, the second most common syntactic form in exemplification with for example and for instance are NPs: they occur in 10-14\% of the corpus examples in both the GE and the EE in the two varieties under consideration, a percentage which is slightly higher in the $\mathrm{EE}$ in the British variety regardless of the marker involved (20-21\% of the cases). An example of nominal exemplifica- 
tion with these markers is provided in (1) above, where the GE is a few countries and the EE Chile, Ghana, and Indonesia). For example and for instance may link a wide variety of syntactic forms (such as prepositional phrases, adverb phrases, adjective phrases, verb phrases or adverbial clauses), although their use is far more infrequent and does not shed any further light on the current use of these markers. (19)-(24) below are cases of weak exemplification showing these various types of GE and EE.

(20) [Adverb phrase + prepositional phrase] Elsewhere, however, as in Leicester, for instance, the land really has dried out, and the arable was mostly in tilth by the middle of March. (LOB, E15 86)

(21) [Prepositional phrase + adverb clause] Contrary to popular belief, a special licence is not one which enables a couple to marry quickly. This special licence is granted by the appropriate Bishop only in exceptional circumstances (for example, when a couple wish to marry in a district where they neither live nor worship or in a place which is not licensed for marriage-a college chapel, etc.). (LOB, F18 127)

(22) [Omitted GE + adverb clause] The date for final payments under the private chattels scheme was fixed at 14th July, 1947, and under the business chattels scheme at 1st October, 1953, but a certain number of claims remain unpaid (for example because the claimant could not be traced) and are thought to amount to about $£ 1,120,000[\ldots]$.

(LOB, H05 123)

(23) [Prepositional phrase + adverb phrase] But sending out warnings by email, fax or telephone at certain times of the day, for example, late at night or early in the morning might not be adequate if occupants are not alert to receive them. (BE06, $\mathrm{H} 20)$

(24) [Omitted GE + adjective phrase] A "limit" in terms of pre-liminal variation may be thought about in common sense terms as a boundary, barrier, the end of something, and so on, that is for example, visible, real, attainable or reachable in some everyday sense. (BE06, J73)

(25) [Omitted GE + verb phrase] He can, for example, present significant university-wide issues to the senate. (BROWN, H30 0280)

There is, however, a special kind of GE which should be considered in detail, namely the omission of the GE (cf. (21), (23), (24)). It is precisely due to examples of this kind that Koktová (1986: 19) claims that "many of the so-called appositive particles can occur in sentences even without an appositive context", ${ }^{11}$ that is, sentences in which the EE does not refer anaphorically to a previous 
general unit. She illustrates her words with (25) below, which does not differ significantly from (26), an example provided by our corpus material.

(26) In the National Park, Terry is going to visit for example the Grand Canyon. (Koktová 1986: 19)

(27) We do not know how much the attraction of students towards universities is the result of their monopoly of the degree-giving power. Suppose, for example, that other types of institution than universities were given permission to award degrees, how would this affect the candidates'choices? (LOB, G58 39)

Although exemplifying constructions of this nature (i.e. with no explicit GE) have been largely disregarded in the literature, they are thoroughly discussed in Webber et al. (2003) and Eggs and McElholm (2013). Thus, Eggs and McElholm (2013: 11) distinguish three different uses of for example, i.e. the exemplifying use (cf. (27)), the selective use (cf. (28)) and the argumentative use (cf. (29)):

(28) Boyce Avenue has played shows with Secondhand Serenade in important venues, for example the Hammersmith Apollo.

(29) a. Boyce Avenue has for example played shows with Secondhand Serenade in the Hammersmith Apollo.

b. Boyce Avenue has played shows with for example Secondhand Serenade in the Hammersmith Apollo.

(30) a. For example Boyce Avenue has played with Secondhand Serenade in the Hammersmith Apollo.

b. Boyce Avenue for example has played with Secondhand Serenade in the Hammersmith Apollo.

Only the exemplifying sequence in (27) consists of two units in apposition, namely important venues (GE) and The Hammersmith Apollo (EE). In other words, only (27) is a prototypical case of exemplification where the GE is overtly mentioned. In turn, in (28) for example is dependent ("parasitic", Webber et al.'s 2003: 566 terminology) on a previous unit: the auxiliary verb has and the preposition with, respectively. Here, a previous, elided GE is easily understood: "Boyce Avenue has done many things this year, for example played shows with Secondhand Serenade in the Hammersmith Apollo" and "Boyce Avenue has played shows with many invited artists, for example Secondhand Serenade in the Hammersmith Apollo". Eggs and McElholm (2013) categorize this example as showing a selective use because, from the very general, implicit GE, the speaker selects one of the many possibilities and provides it as the EE. The authors group these two uses (namely, exemplification and selection) into the wider label of descriptive uses because 
"they both operate on the level of the sentence [they connect phrases] and are thus to be understood as complete communicative units" (Eggs and McElholm 2013: 12; italics in the original). In turn, (29) represents argumentation in that for example connects whole sentences rather than phrases: "The argumentative uses, in contrast, are transphrastic, since they refer to preceding sentences together with which they form a type of text or genre, namely argumentation" (Eggs and McElholm 2013: 12).

\section{Conclusions}

This study has revealed considerable formal and functional dissimilarities between two sets of English EMs, namely including and included, on the one hand, and for example and for instance, on the other, but it has also pointed at some intraset differences. In the data analyzed, included (which is scarcely recorded in the material) exclusively links nominal units and always follows the EE. Likewise, including (which always precedes the EE) favors the use of NPs too. As a consequence, most exemplifying constructions with including and included carry out functions typically performed by NPs. All in all, the use of these two EMs suggests that both items have remained very close to their source form (i.e. the verb to include) after their process of grammaticalization. As a matter of fact, the relationship between these two EMs and their EE is analogous to the relationship between the verb to include and its DO. However, interestingly enough, including can now connect new, unexpected types of forms, such as adverb phrases, prepositional phrases or sentences. The fact that a preposition like including is broadening its structural scope and can now introduce non-nominal elements suggests that this form is advancing forwards in its process of grammaticalization.

When it comes to the EMs for example and for instance, they can link a wider variety of units in exemplification, such as NPs, prepositional phrases, adjective phrases, adverb phrases, various types of clauses and sentences. However, they show a clear tendency to link sentences (especially in AmE), which seems to be caused by the semasiology of the nouns example and instance themselves: the nominal forms example and instance may refer to a long narrative, which is precisely what the EE with for example and for instance looks like in many corpus examples. In other cases, the GE may also be omitted with these two forms. Additionally, these markers show a great deal of syntagmatic freedom as they may either precede, follow or intervene in the middle of the EE. The different positions which the EMs may occupy in the exemplifying sequence may bring about different implications. Thus, $\mathrm{P} 1$ is the unmarked position for connectors of this kind, and it performs a more neutral linking function; in turn, $\mathrm{P} 2$ is used to isolate and emphasize a part of the EE; finally, an EM which comes in P3 may add various pragmatic nuances. For example, when used in final position the marker may indicate that the speaker/writer does not want to impose his/her own choice and that the example selected is just one of the possibilities included within the 
previous GE, but it is the addressee's task to either accept it or think of any other possibility. In other words, the EM is used as a hedge to attenuate the meaning of a statement. On the contrary, final position may also be used to emphasize the example chosen. For instance is becoming increasingly common in this position, which may suggest that it is developing a discursive function. Although the frequencies of the two periphrastic markers in these three positions fluctuate from one decade to the next in the two varieties under analysis, the use of for instance in P3 is clearly on the rise, which indicates that this EM is increasingly used for intersubjective purposes.

\section{Notes}

For the sake of clarity, all exemplifying sequences are provided in italics.

Note, however, that for Meyer (1992: 77) including and included are markers of particularization rather than exemplification. They seem to be in fact half way between these two categories of appositional markers of inclusion, as shown in Rodríguez-Abruñeiras (2017).

3 The exemplifying use of including is provided in the Oxford English Dictionary (OED) under the entry for including as a preposition: 'Used to indicate that the specified person or thing is part of the whole group or category being considered: with the inclusion of' (OED, s.v. including, prep.).

$4 \quad$ It does not go unnoticed that Pullum and Huddleston's definition of preposition is much wider than what is normally labelled as such in mainstream grammars: they include under this term certain conjunctions (with three exceptions: whether, if -when it is equivalent to whether- and that; see de Haan 2005). Although prepositions are here regarded in a much more restrictive way, their words are applicable to the examples of including as EM.

$5 \quad$ Quirk et al. (1985: 1303) apply the term strict apposition to those cases in which the first and the second units involved in an appositional construction belong to the same syntactic class, whereas apposition is weak when the two elements have different forms. Since exemplification is traditionally considered as a subtype of apposition (as mentioned in Section 1), the distinction strict vs. weak also applies to the exemplifying constructions under analysis.

$6 \quad$ Notice that in (13) a NP and an -ing clause are coordinated in the EE. However, as mentioned above, -ing clauses behave like NPs, hence the possibility of linking these two forms in the EE.

$7 \quad$ Eggs and McElholm (2013: 11) discuss the moveable character of EMs like for example, which is "subject to virtually no position restrictions". They provide the following instance to show all the potential sentential slots that for example can occupy: "(For example) The band Boyce Avenue (for example) has (for example) played shows (for example) with (for example) Secondhand Serenade (for example) in important venues, such as (FOR EXAMPLE) the Hammersmith Apollo."

8 Information on the pragmatic implications derived from the different clausal slots is based on Aijmer (1997: 24), Fanego (2010), Beeching and Detges (2014: 11), Haselow (2015: 157) and Degand and van Bergen (2016: 11).

$9 \quad$ In this regard, Eggs and McElholm (2013: 20) claim that "only if the example markers [...] are anteposed in exemplifications do they function as connectors; in all other cases they function as discourse markers".

10 Note, however, that this has not always been the case. Evidence from the $O E D$ shows that the meaning of instance as an example of a general statement coexisted in the EModE period with another meaning which was exactly its opposite: 'A case adduced in objection to or disproof of a universal assertion (= medieval Latin instantia, Greek हैv $\sigma \tau \alpha \sigma \iota \varsigma)$ Obs.' (OED, 
s.v. instance $\mathrm{n}$., III.5). In other words, instance was not only used with the meaning 'example' but also with that of 'counterexample' of a general statement, as in "I am an instance to proue the contrary" (OED, s.v. instance n., III.5). The last example of instance with this meaning provided by the OED dates from the turn of seventeenth century.

11

Note in this regard that in Section 1 above the definition of exemplification referred to prototypical exemplification.

\section{Acknowledgement}

For generous financial support, I am grateful to the Spanish Ministry of Economy and Competitiveness (grant FFI2017-82162-P)

\section{Primary sources}

AE06: The American English 2006 Corpus. Compiled by Paul Baker. Lancaster University. BE06: The British English 2006 Corpus. 2008. Compiled by Paul Baker. Lancaster University. BROWN: A Standard Corpus of Present-Day Edited American English. 1964. Compiled by W. N. Francis and $\mathrm{H}$. Kučera. Brown University.

FLOB: Freiburg-Lob Corpus of British English. 1999. Compiled by Christian Mair. Albert-Ludwigs-Universität Freiburg.

FROWN: Freiburg-Brown Corpus of American English. 1999. Compiled by Christian Mair. AlbertLudwigs-Universität Freiburg.

LOB: Lancaster-Oslo/Bergen Corpus. 1976, 1986. Compiled by Geoffrey Leech et al. Lancaster University, University of Oslo and University of Bergen.

\section{References}

Aijmer, Karin (1997) I think: An English modal particle. In: Swan, Toril and Olaf Jansen Westvik (eds.) Modality in Germanic Languages. Historical and Comparative Perspective. Berlin: Mouton de Gruyter, 1-47.

Beeching, Kate and Ulrich Detges (2014) Introduction. In: Beeching, Kate and Ulrich Detges (eds.) Discourse Functions at the Left and Right Periphery. Crosslinguistic Investigations of Language Use and Language Change. Leiden and Boston: Brill, 1-23.

Brinton, Laurel J. and Elizabeth Closs Traugott (2005) Lexicalization and Language Change. Cambridge: Cambridge University Press.

Brosius, Hans Bernd and Anke Bathelt (1994) The utility of exemplars in persuasive communications. Communication Research 21, 48-78.

Bybee, Joan (2003) Cognitive processes in grammaticalization. In: Tomasello, Michael (ed.) The New Psychology of Language. Cognitive and Functional Approaches to Language Structure. New Jersey: Lawrence Erlbaum Associates, 145-167.

De Haan, Pieter (2005) Review of Huddleston, Rodney and Geoffrey Pullum's (eds.) The Cambridge Grammar of the English Language. Cambridge: Cambridge University Press. 2002. Reviewed in English Studies 86, 335-341.

Degand, Liesbeth and Geertje van Bergen (2016) Discourse markers as turn-transition devices: Evidence from speech and instant messaging. Discourse Processes 00 (0), 1-25.

Eggs, Ekkehard and Dermot McElholm (2013) Exemplifications, Selections and Argumentations. Frankfurt am Main: Peter Lang GmbH. 
Fanego, Teresa (2010) Paths in the development of elaborative discourse markers: Evidence from Spanish. In: Davidse, Kristin, Lieven Vandelanotte and Hubert Cuyckens (eds.) Subjectification, Intersubjectification and Grammaticalization. Berlin: Mouton de Gruyter, 197-237.

Fernández-Bernárdez, Cristina (1994-1995) Marcadores textuales de 'ejemplificación' textual. Estudios de Lingüistica 10, 103-144.

Gibson, Rhonda and Dolf Zillmann (1994) Exaggerated versus representative exemplification in news reports: Perception of issues and personal consequences. Communication Research 21, 603-624.

Haselow, Alexander (2015) Left vs. right periphery in grammaticalization. The case of anyway. In: Smith, Andrew D.M., Graeme Trousdale and Richard Waltereit (eds.) New Directions in Grammaticalization Research. Amsterdam and Philadelphia: John Benjamins Publishing Company, $157-186$.

Hoffmann, Sebastian (2005) Grammaticalization and English Complex Prepositions. A Corpusbased Study. London and New York: Routledge.

Hopper, Paul J. (1991) On some principles of grammaticization. In: Traugott, Elizabeth Closs and Bernd Heine (eds.) Approaches to Grammaticalization. Vol. I: Focus on Theoretical and Methodological Issues. Amsterdam and Philadelphia: John Benjamins, 17-35.

Hopper, Paul J. and Elizabeth Closs Traugott (2003) [1993]. Grammaticalization, $2^{\text {nd }}$ edition. Cambridge: Cambridge University Press.

Hyland, Ken (2007) Applying a gloss: Exemplifying and reformulating in academia discourse. Applied Linguistics 28 (2), 266-285.

Koktová, Eva (1986) Apposition as a pragmatic phenomenon in a functional description. University of East Anglia Papers in Linguistics 23, 39-79.

König, Ekkehard and Bernd Kortmann (1991) On the reanalysis of verbs as prepositions. In: Rauh, Gisa (ed.) Approaches to Prepositions. Túbingen: Gunter Narr, 109-125.

Kuryłowicz, Jerzy (1975) Esquisses Linguistiques II. München: Wilhelm Fink.

Langacker, Ronald Wayne (1977) Syntactic reanalysis. In: Li, Charles N. (ed.) Mechanisms of Syntactic Change. Austin: University of Texas Press, 57-139.

Lehmann, Christian (2002) [1995]. Thoughts on Grammaticalization, $2^{\text {nd }}$ edition. München/Newcastle: Lincom Europa. (First published as Thoughts on Grammaticalization: A Programmatic Sketch. No. 48 in the series Arbeiten des Kölner Universalien Projekts, University of Cologne, Institut für Sprachwissenschaft).

Lightfoot, Douglas (2011) Grammaticalization and lexicalization. In: Narrog, Heiko and Bernd Heine (eds.) The Oxford Handbook of Grammaticalization. Oxford: Oxford University Press, 438-449.

Lischinsky, Alon (2008) Examples as persuasive argument in popular management literature. Discourse and Communication 2, 243-269.

Lyons, John D. (1989) Exemplum: The Rhetoric of Example in Early Modern France and Italy. New Jersey: Princeton University Press.

Meyer, Charles F. (1992) Apposition in Contemporary English. Cambridge: Cambridge University Press.

OED: Oxford English Dictionary. Online: <http://www.oed.com/>

Perry, Stephen D. and William J. Gonzenbach (1997) Effects of news exemplification extended: Considerations of controversiality and perceived future opinion. Journal of Broadcasting and Electronic Media 41 (2), 229-244.

Pullum, Geoffrey K. and Rodney Huddleston (2002) Prepositions and preposition phrases. In: Huddleston, Rodney and Geoffrey K. Pullum (eds.) The Cambridge Grammar of the English Language. Cambridge: Cambridge University Press, 597-662.

Quirk, Randolph, Sidney Greenbaum, Geoffrey Leech and Jan Svartvik (1985) A Comprehensive Grammar of the English Language. London: Longman.

Rodríguez-Abruñeiras, Paula (2017) Exemplification then and now: A historical overview of English exemplifying markers. Miscelanea. A Journal of English and American Studies 55, 87-107. 
Stump, Gregory (2009) Derivation and function words. In: Rochelle, Lieber and Pavol Štekauer (eds.) The Oxford Handbook of Derivational Morphology. Oxford: Oxford University Press, 317-137.

Webber, Bonnie, Matthew Stone, Aravind Joshi and Alistair Knott (2003) Anaphora and discourse structure. Computational Linguistics 29 (4), 545-587.

Wichmann, Anne, Anne-Marie Simon-Vandenbergen and Karin Aijmer (2010) How prosody reflects semantic change: A synchronic case study of of course. In: Davidse, Kristin, Lieven Vandelanotte and Hubert Cuyckens (eds.) Subjectification, Intersubjectification and Grammaticalization. Berlin: Mouton de Gruyter, 103-154.

Zillmann, Dolf and Hans-Bernd Brosius (2000) Exemplifications in Communication: The Influence of Case Reports on the Perception of Issues. Mahwah, New Jersey: Lawrence Elrbaum Associates.

Paula Rodríguez-AbruñeIRas is a Lecturer in English Language and Linguistics in the Department of English and German Studies at the Universitat de València (Spain). She holds a European Doctorate in Historical Linguistics from the University of Santiago de Compostela. Her research interests include Corpus Linguistics, Linguistic Variation, Historical Linguistics, New Englishes and Critical Discourse Analysis. She is currently a member of GENTEXT (Gender, Language and Sexual (In)equality, Universitat de València), IULMA (Interuniversity Institute of Applied Modern Languages, Universitat de València) and an affiliated member of LVTC (Language Variation and Textual Categorization, Universidade de Vigo).

Address: Dr Paula Rodríguez-Abruñeiras, IULMA/Department of English and German, Universitat de València, Avda. Blasco Ibañez, 32, E-46010 València, Spain. [email: paula.rodriguez@uv.es] 
